\title{
Preparation and Characterization of Molecularly Imprinted Uniform-sized Poly(4VP-co-EGDMA) Microgels
}

\author{
Kong-Soo KIM,,${ }^{1} \dagger$ Ji-Hoon LEE, ${ }^{1}$ Myoung Ho KIM, ${ }^{2}$ and Suk-Hyung $\mathrm{CHO}^{3}$ \\ ${ }^{1}$ Dept. of Ind. and Eng., Chungbuk National University, Cheongju, Chungbuk 361-763, Korea \\ ${ }^{2}$ LG Chemical Ltd. Cheongwon Chungbuk 363-911, Korea \\ ${ }^{3}$ Dept. of Medical Materials., Hyejeon College, San 16, Namjang-ri, Hongsung-eup, \\ Hongsung-gun, Chungnam 350-702, Korea
}

(Received January 11, 2005; Accepted June 9, 2005; Published September 15, 2005)

\begin{abstract}
Molecularly imprinted uniform-sized poly(4VP-co-EGDMA) microgels were prepared from 4-vinyl pyridine (4VP) monomer and ethylene glycol dimethacrylate (EGDMA) as crosslinking agent using monodisperse linear polystyrene seed particles by multi-step swelling polymerization method.

The polymerization conditions were chosen in such a way that the formation of solution complexes between 4VP and the template (N-protected amino acid) prior to polymerization would be favored. The effects of polymerization parameters such as weight ratio of the monomer/seed and diluent/monomer, the concentration of crosslinking agent on the average particle size and pore size distribution were investigated.

The molecularly imprinted polymer microgels were utilized as a stationary phase in HPLC. In the chromatographic mode, resolution of the enantiomers of Cbz-L,D-aspartic acid (Cbz: carbobenzoxy) were resolved with the imprinted polymer. [DOI 10.1295/polymj.37.669]

KEY WORDS Polymer Microgel / Molecularly Imprinted Polymer / Seed Polymerization /

Monodisperse Polymer Particle /
\end{abstract}

With the development of industry, high accuracy in terms of selectivity and reproducibility is required in product analysis, separation and purification, etc. In response to the requirement, high performance liquid chromatography (HPLC) and gel permeation chromatography (GPC) are widely used as analysis methods, and porous polymer gels are used as packing materials of chromatographic column. In particular, because polymer gels are superior in adsorption and separation properties, those are used in adsorption and separation of compounds, drug delivery system and biocatalyst. ${ }^{1-5}$

Recently, molecularly imprinted polymer (MIP) microgels, which have the function of molecular recognition, are studied much for adsorption and separation of optical isomers from bioactive substances such as amino acids, proteins, nucleic acids and steroids. ${ }^{6-10}$ The separation mechanism of chromatography packed with molecularly imprinted polymer gels is not by covalent bond but by the binding site of non-covalent binding such as hydrogen bond and electrostatic interaction. ${ }^{11-19}$

In order to synthesize the molecularly imprinted polymer gels are used monomers with polar functional group such as carboxylic acids, carbonates, carboxylic ester and acrylamide, particularly, vinyl pyridine, methacrylic acid, methacryl amide, acryl amide, etc. Most of molecularly imprinted polymers were pre- pared by bulk polymerization, and used to adsorb and separate the chiral isomers from amino acids, drugs, bioactive substances, etc.

The monodisperse, porous and spherical MIP microgel particles are useful as stationary phase in HPLC. In generally, the particle size and pore size of the packing materials for HPLC are very important for highly efficient separation. Most of all monodisperse porous particles having macroporous structures are the most efficient materials for macroseparation processes. ${ }^{20,21}$

The role of hydrogen bonding in molecular recognition has been the focus of much attention recently. It has long been known that carboxylic acids form hydrogen bonds with a great variety of polar functionalities, including carbamates, amides, carboxylic acids and carboxylic esters, and that the hydrogen bonds connection one carboxylic acid with another are very strong. ${ }^{15}$ Imprinted polymers have been prepared as antibody and receptor mimics, as sensor materials, as chromatography stationary phase for separation and purification purposes, and attempts have also been made to prepare imprinted polymers with certain catalytic properties. The MIP microgels would be analysed for their ability to separate the enantiomers of $\mathrm{N}$-protected amino acid and also for their ability to separate the original print molecule from a mixture of compounds similar in structure. 
K.-S. KIM et al.

Table I. Preparation of Molecularly Imprinted Poly(4VP-co-EGDMA) microgels by Seed Polymerization

\begin{tabular}{cccccc}
\hline Sample No. & $\begin{array}{c}\text { Monomer/ } \\
\text { Seed }(\mathrm{g} / \mathrm{g})\end{array}$ & $\begin{array}{c}\text { EGDMA/ } \\
\text { Monomer } \\
(\mathrm{mol} \%)\end{array}$ & $\begin{array}{c}\text { Diluent/ } \\
\text { Monomer } \\
(\mathrm{g} / \mathrm{g})\end{array}$ & $\begin{array}{c}\text { Particle diameter } \\
(\mu \mathrm{m})\end{array}$ & $\begin{array}{c}\text { Yield } \\
(\%)\end{array}$ \\
\hline 1 & 12.5 & & & 4.0 & 90.5 \\
2 & 16.7 & 80 & $1 / 1$ & 4.5 & 94 \\
3 & 25 & & & None particle & 0 \\
4 & 50 & 60 & $1 / 1$ & None particle & 0 \\
5 & 25 & 70 & & $2-6.2$ & 96.6 \\
6 & & 90 & 4.7 & 5.2 & 97 \\
\hline 8 & 25 & 80 & $2.0 / 1$ & $5.0-6.0$ & 95 \\
\hline
\end{tabular}

- Reaction condition; Temperature: $70^{\circ} \mathrm{C}$, Time: 8-10 h, Initiator: 2.2'-azobis(2,4-dimetyl valero nitrile) (V-65), Emulsifier: sodium dodecyl sulfate, Template molecule: protected amino acid $1.5 \mathrm{~g}$.

In this study, as basic research for selective adsorption and separation of specific chiral isomer molecules, molecularly imprinted poly(4-vinyl pyridineco-ethyleneglycol dimethacrylate), poly(4VP-coEGDMA) microgels were synthesized by multi-stage swelling method. Also, the size, shape, surface area and porosity of molecularly imprinted microgel particles were examined according to the weight ratio of monomer/seed, diluent/monomer and the mol ratio of monomer/crosslinking agent. The MIP microgels also used as stationary phase in HPLC column, and separation characteristics of the MIP microgels for the enantiomers of amino acid were investigated.

\section{EXPERIMENTAL}

\section{Reagents}

4-Vinyl pyridine (4VP) (Aldrich) was distilled under reduced pressure in nitrogen atmosphere and kept in a refrigerator before use. Styrene (St) (Junsei Chemical, Japan) and ethylene glycol dimethacrylate (EGDMA) (Aldrich) were washed with $10 \% \mathrm{NaOH}$ solution and distilled under reduced pressure in nitrogen atmosphere. 2.2'-Azobis(2,4-dimetyl valero nitrile) (V-65) (Wako Pure Chemical) was used as it was purchased. Polyvinyl alcohol (PVA) and polyvinyl pyrrolidone (PVPD) (Junsei Chemical) were used as dispersant. D- and L-Cbz-aspartic acid were obtained from Aldrich $(\mathrm{Cbz}=$ carbobenzoxy).

\section{Synthesis of MIP Microgels}

Monodisperse, porous molecularly imprinted poly(4VP-co-EGDMA) microgels were synthesized by multi-stage swelling method. First of all, $0.08 \mathrm{~g}$ of sodium dodecyl sulfate and $1 \mathrm{~mL}$ of dibutyl phthalate were added in to distilled water to make micro-emulsion and $0.4 \mathrm{~g}$ of polystyrene (PS) seeds prepared by emulsion polymerization method, which was describ- ed by $\mathrm{Kim}^{22}$ else where. PS seeds were prepared by adjusting the ratio of ethanol/water $(95 / 5 \mathrm{v} / \mathrm{v})$ in the presence of $1.7 \mathrm{wt} \%$ PVPD dispersant and aerosol-OT auxiliary dispersant. The PS seeds with particle size of used $1.4 \mu \mathrm{m}$. Then, $1.2 \mathrm{~g}$ of $4 \mathrm{VP}$ monomer, $8.8 \mathrm{~g}$ of EGDMA, which is a crosslinking agent, and $14.6 \mathrm{~g}$ of toluene, which is a diluent, were dispersed with PS seed particles. And then, $1.5 \mathrm{~g}$ of protected amino acid (N-Cbz-L,D-aspartic acid), which is template molecule, was dispersed together. The reaction mixture was polymerized at $70^{\circ} \mathrm{C}$ in nitrogen atmosphere. In addition, the template molecules containing in porous microgels were extracted out with acetonitrile for $24 \mathrm{~h}$, and washed with acetone and methanol several times, and MIP microgels were obtained.

\section{Particle Size and Surface Morphology}

Molecularly-imprinted polymer (4VP-co-EGDMA) microgels were spread thinly on a glass sample plate and vacuum vapor-deposited with gold, and their particle size and surface morphology of the MIP microgels were observed using a scanning electron microscope (Hitachi S570). In addition, a fixed quantity of MIP microgels were dispersed using an ultrasonic wave generator, and the particle size distribution of the dispersed suspension was measured with a particle size analyzer (Malvern Autosizer-II).

\section{Specific Surface Area and Pore Size}

By the BET method, the specific surface area of MIP microgels was measured using a surface area analyzer (Micrometrics Instrument, ASAP 2405), and the pore size was estimated.

\section{Separation Characteristics of MIP Microgels for HPLC}

The MIP microgel particles were suspended in chloroform-acetonitrile $(17: 3, \mathrm{v} / \mathrm{v})$ by sonication and 

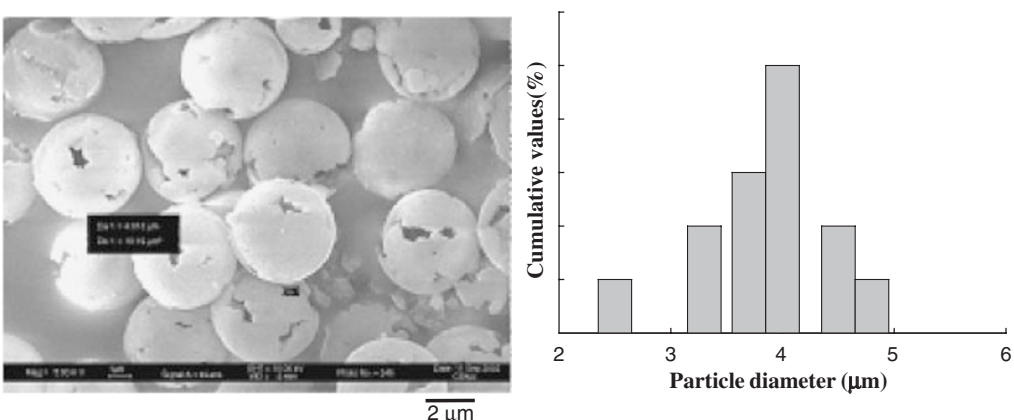

(A)
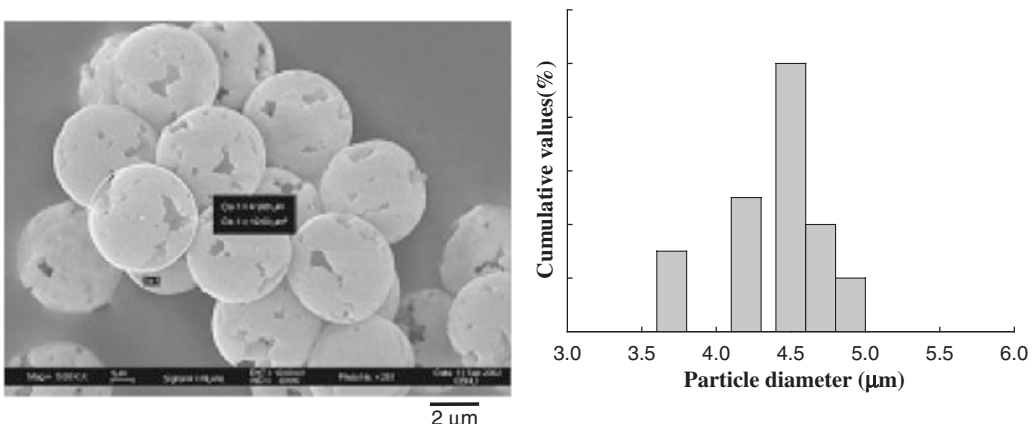

(B)
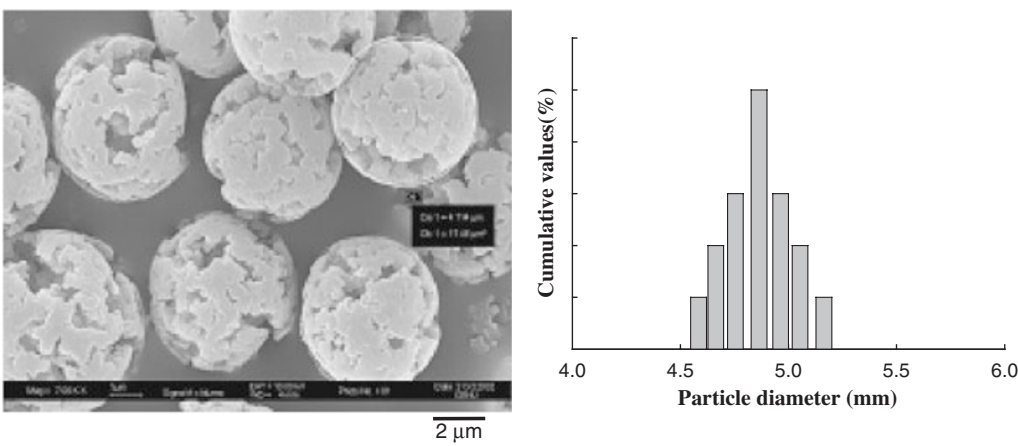

(C)

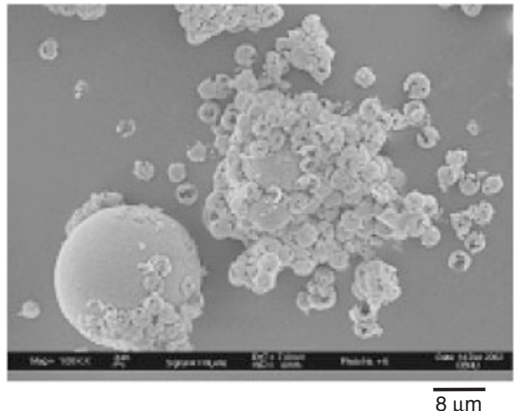

(D)

Figure 1. SEM images of the molecularly imprinted poly(4VP-co-EGDMA) microgels; Wt ratio of monomer/seed: (A) 12.5/1 (B) $16.7 / 1$ (C) $25 / 1$ (D) $50 / 1$.

packed into $200 \mathrm{~mm} \times 4.5 \mathrm{~mm}$ stainless-steel columns with acetonitrile as solvent at 200, 500, 1000, $1500 \mathrm{psi}$ using an standard slurry packer (Alltech, USA). The slurry was compressed by $\mathrm{N}_{2}$ gas and the injected into the column from a slurry reservoir. The columns were then washed on-line with acetonitrile until a stable baseline was obtained. The print molecules were al- most quantitatively removed from the polymer by this treatment, as judged by Waters model 440 UV detector measurements. High performance liquid chromatography (HPLC) were performed isocratically with the acetonitrile-chloroform at a flow-rates of $0.1 \mathrm{~mL} /$ min. Detection was at $250 \mathrm{~nm}$. A mixture of $5 \mu \mathrm{g}$ of each enantiomers of a D- and L-Cbz-aspartic acid, 


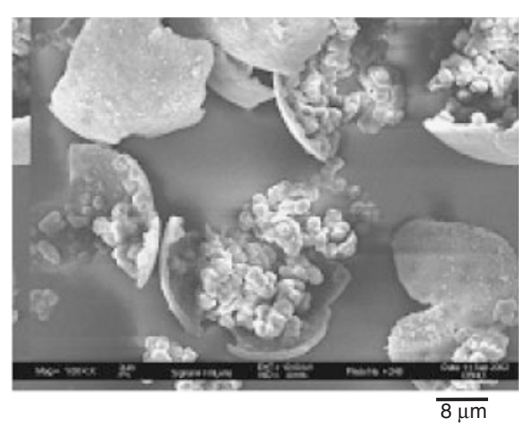

(A)
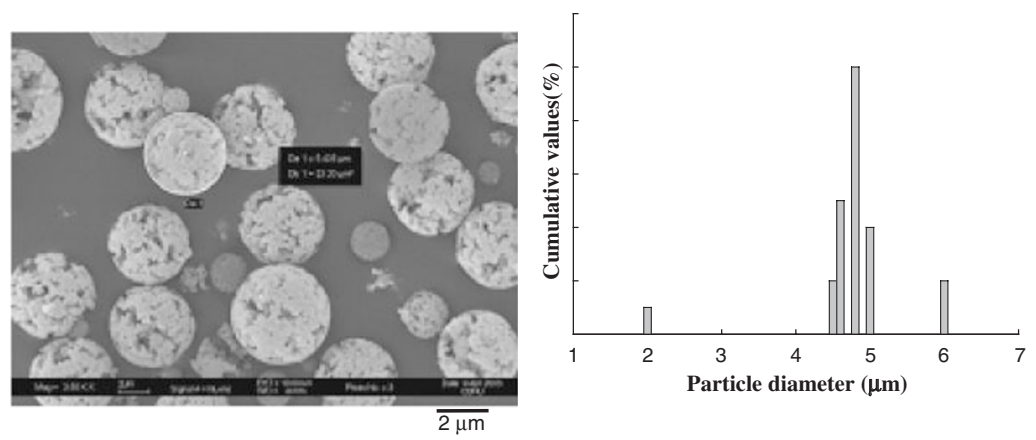

(B)
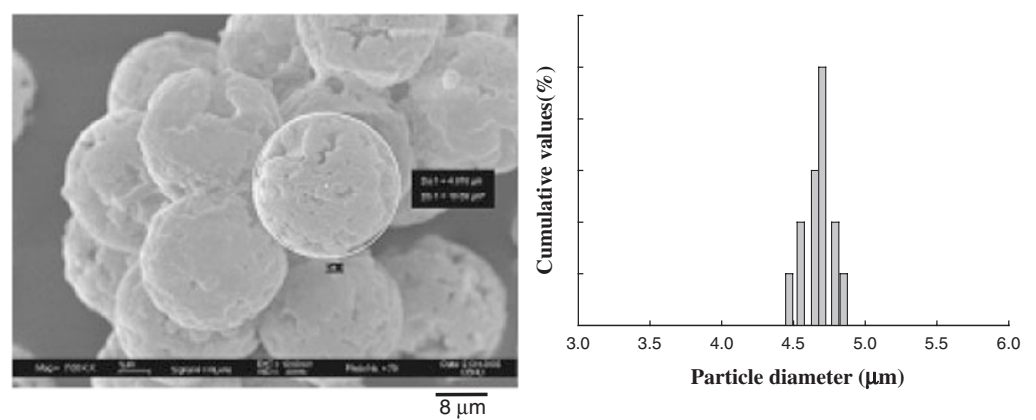

(C)

Figure 2. SEM images of the molecularly imprinted poly(4VP-co-EGDMA) microgels; Mol \% of EGDMA: (A) 60 (B) 70 (C) 90 , respectively.

prepared in the mobile phases, was injected for analysis in a total volume of $20 \mu \mathrm{L}$. Enantiomeric resolution was confirmed by separate injections of each of the enantiomers. ${ }^{8,15}$

\section{RESULTS AND DISCUSSION}

\section{Synthesis of MIP Microgels}

The MIP microgel particles with the range of 4.3$5.0 \mu \mathrm{m}$, were synthesized using seed emulsion polymerization. The mixed solvent of toluene/isoamyl alcohol were used as diluents. The result of synthesis of the MIP microgels containing $1.5 \mathrm{~g}$ of protected amino acid was shown in Table I.

Monodisperse porous MIP microgels were obtained from the mole ratio of 4VP/EGDMA of $60-90 \mathrm{~mol} \%$ and different weight ratio of seed/diluent by seed polymerization. In preparing the MIP microgels, the weight ratio of diluent/monomer was $1.5 / 1.0$, the weight ratio of toluene/iso-amyl alcohol was 14.5/ 0.5 , and the concentration of the initiator to total monomers were $10 \mathrm{wt} . \%$.

The MIP microgels were prepared from the weight ratio of monomer/seed varying with $12.5 / 1,16.7 / 1$, $25 / 1$ and 50/1. The particle size and size distribution of the MIP microgels using SEM and light scattering measuring method were shown in Figure 1. When the weight ratio of monomer/seed was varied with $12.5 / 1,16.7 / 1,25 / 1$, monodisperse polymer microgels could be obtained but with increasing seed/ monomer ratio, microgel particles tended to break in the process of extracting seeds. In general, the particle 

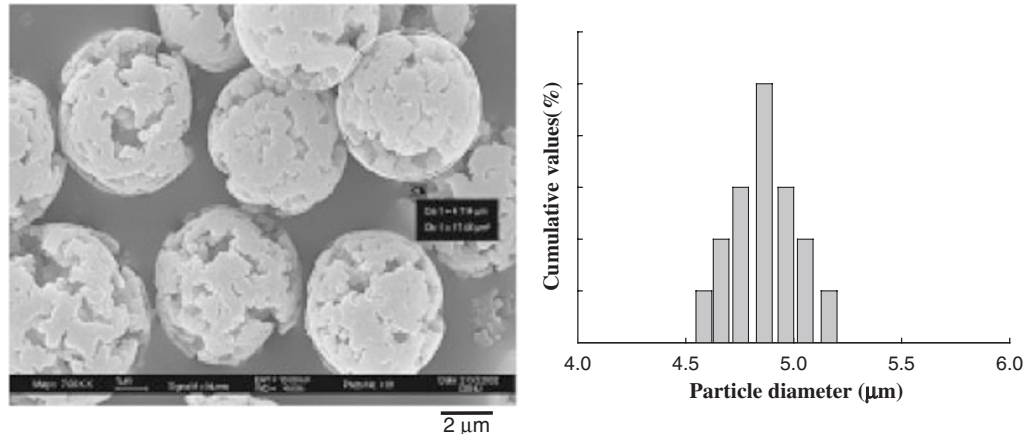

(A)
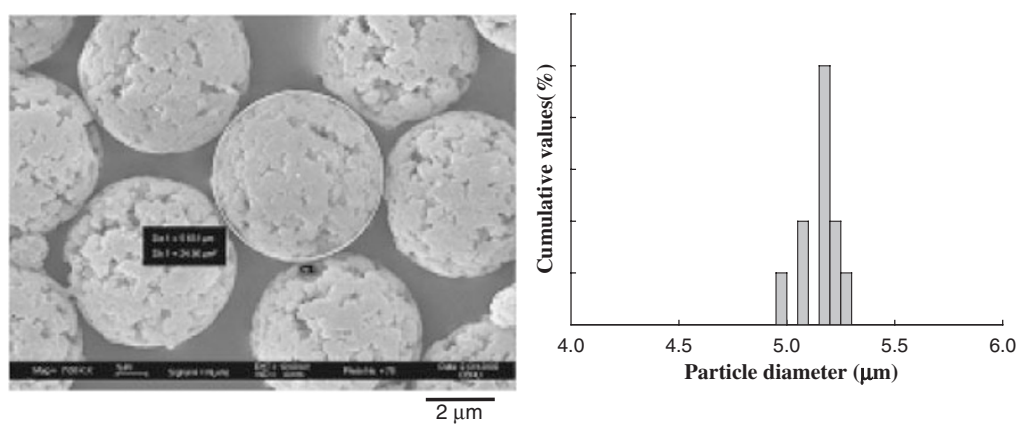

(B)
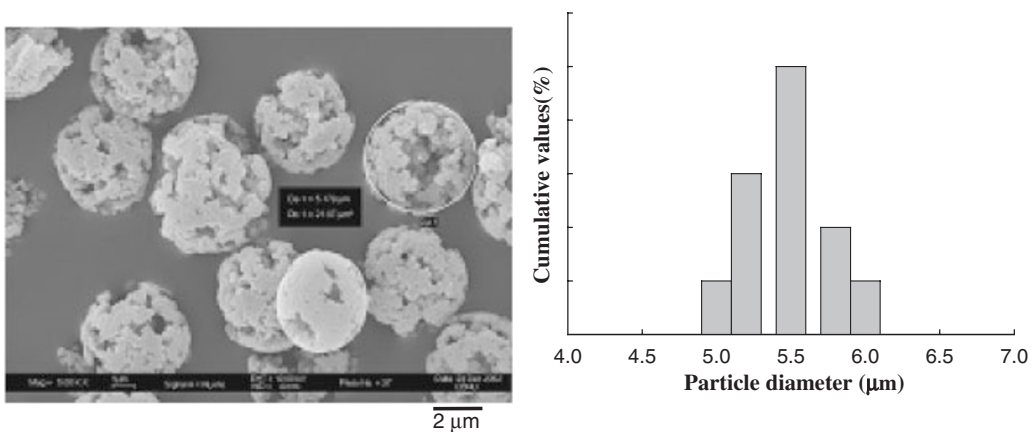

(C)

Figure 3. SEM images of the molecularly imprinted poly(4VP-co-EGDMA) microgels; Wt. ratio diluent/monomer: (A) 1.0/1 (B) $1.5 / 1$ (C) $2.0 / 1$.

shape of MIP microgels was spherical, the particle size distribution was monodisperse, and the conversion of the microgels were over around $90.5 \%$.

SEM images of the MIP microgels synthesized with the weight ratio of monomer/seed fixed at $25 / 1$ and the mole ratio of crosslinking agent to monomer varying with 60,70, 80 and $90 \mathrm{~mol} \%$ were shown in Figure 2. As shown in the figure, the shape of particles became uniform and pores developed with the increase of the quantity of crosslinking agent, and the particle size slightly decreased from $70 \mathrm{~mol} \%$.

There are three roles of diluent in seed polymerization. First, emulsion containing monomer, crosslinking agent and initiator behave as oil phase dispersed in water. Second, as a swelling agent that swells PS seed particles, it is important to select a solvent, the solubility parameter of which is similar to that of seed polymer. Third, it works as a substance forming pores through being extracted together with linear PS seed polymer after reaction, forming macropore and mesopore on the surface of polymer microgels. In addition, diluent increases the irregularity of phase separation inside seed, which is swollen linear polymer, and consequently increases the specific surface area and the volume of pores of polymer microgels.

In the present polymerization system, the method of forming pore structure using the mixture of linear polymer PS seeds and inactive diluent of toluene/ iso-amyl alcohol was extremely complicated because poly(4VP-co-EGDMA) microgels are non-solvent to the diluents. At the initial stage, monomer is a good solvent to diluent, but as polymerization proceeds, phase separation occurs in poly(4VP-co-EGDMA) microgels between PS seeds and non-solvent. ${ }^{22}$ Thus the porosity of microgel particles will be formed by space made by phase separation between PS seeds 

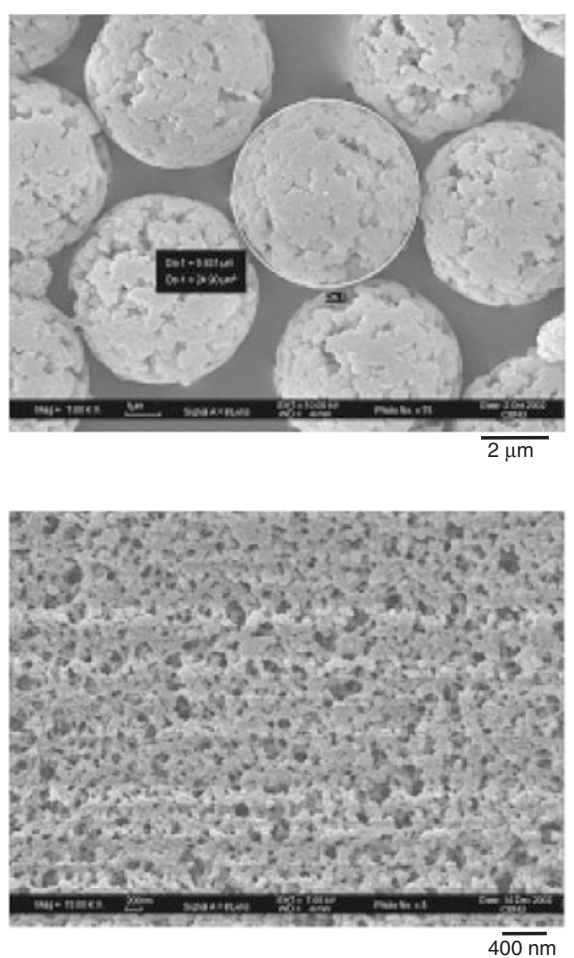

Figure 4. SEM images of the molecularly imprinted poly(4VP-co-EGDMA) microgels surface.

and poly(4VP-co-EGDMA) microgels.

Figure 3 shows SEM images of the microgels with the weight ratio of monomer/seed of $25 / 1$, the concentration of crosslinking agent of $80 \mathrm{~mol} \%$, and the weight ratio of diluent/monomer varying with 1.0/1, 1.5/1 and 2.0/1. As shown in the Figure 3, the microgel particles were best prepared when the weight ratio of diluent/monomer was $1.5 / 1$. In addition, particle size was smaller but the development of pores on the particle surface was higher when the weight ratio of diluent/monomer was $1.0 / 1$ than when it was $1.5 / 1$, because PS seeds were not swollen sufficiently due to lack of the quantity of toluene and iso-amyl alcohol inside emulsion. The microgels were not monodisperse and microgels broke when the weight ratio of diluent/monomer was higher than 2.0/1. Such a phenomenon is understood that, as the quantity of diluent is relatively larger than the number of particles of dispersed monomer and PS seeds, PS seed particles react without maintaining a uniform shape when they swell by the diluent.

On the other hand, the pore structure of porous microgels can be divided into three parts, macropore, mesopore and micropore. ${ }^{10}$ The surface and a broken section of the microgels were shown in Figure 4. As shown in the SEM image, polymer microgels are an aggregate of microspheres interconnected, and space between aggregate in the polymerization system including a substance creating pores is the range of

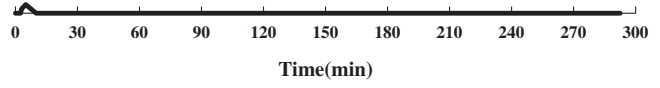

(a) Blank

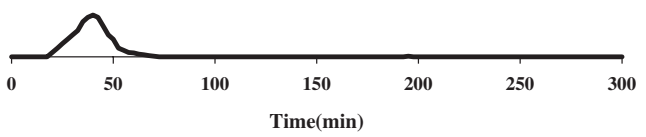

(b) N-Cbz-L-aspartic acid

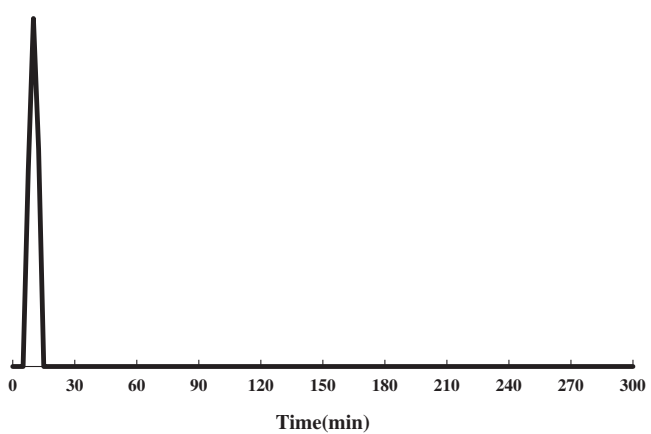

(c) N-Cbz-D-aspartic acid

Figure 5. HPLC profiles of N-Cbz-L,D-aspartic acid on the poly(4VP-co-EGDMA) microgels; Solvent ratio (acetonitrilechloroform, $90 / 10 \mathrm{v} / \mathrm{v})$.

macropore $(500 \AA)$. Furthermore, microspheres are nuclei that have grown at the initial stage of polymerization, and space between microspheres forming an aggregate is the range of mesopore (100-500 $\AA$ ) and space inside microspheres is the range of micropore (less than $100 \AA$ ).

The results of BET measurement of monodisperse porous poly(4VP-co-EGDMA) microgels were shown in Table II. With the increase of the particle size of the microgels, the mean pore size changed from $83.67 \AA(4.7 \mu \mathrm{m})$ to $44.95 \AA(4.8 \mu \mathrm{m})$ and $67.12 \AA$ $(5.2 \mu \mathrm{m})$, and the mean surface area from 272.30 $\mathrm{m}^{2} / \mathrm{g}(4.7 \mu \mathrm{m})$ to $242.67 \mathrm{~m}^{2} / \mathrm{g}(4.8 \mu \mathrm{m})$ and 197.81 $\mathrm{m}^{2} / \mathrm{g}(5.2 \mu \mathrm{m})$.

The purpose of this study was to use molecular imprinting for the preparation of a synthetic polymer microgels selective for $\mathrm{N}$-protected amino acid. The clinically useful N-Cbz-L-aspartic acid was used as

Table II. BET Data of Monodisperse Porous Moleculary Imprinted Poly(4VP-co-EGDMA) microgels

\begin{tabular}{cccc}
\hline $\begin{array}{c}\text { Particle size } \\
(\mu \mathrm{m})\end{array}$ & $\begin{array}{c}\text { Surface area } \\
\left(\mathrm{m}^{2} / \mathrm{g}\right)\end{array}$ & $\begin{array}{c}\text { Total pore volume } \\
(\mathrm{cc} / \mathrm{g})\end{array}$ & $\begin{array}{c}\text { Pore diameter } \\
(\AA)\end{array}$ \\
\hline 4.7 & 272.30 & 0.56 & 83.66 \\
4.8 & 242.67 & 0.27 & 44.95 \\
5.2 & 197.81 & 0.33 & 67.12 \\
\hline
\end{tabular}




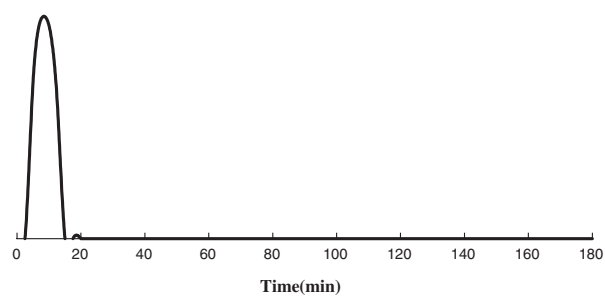

(a)Unimprinted

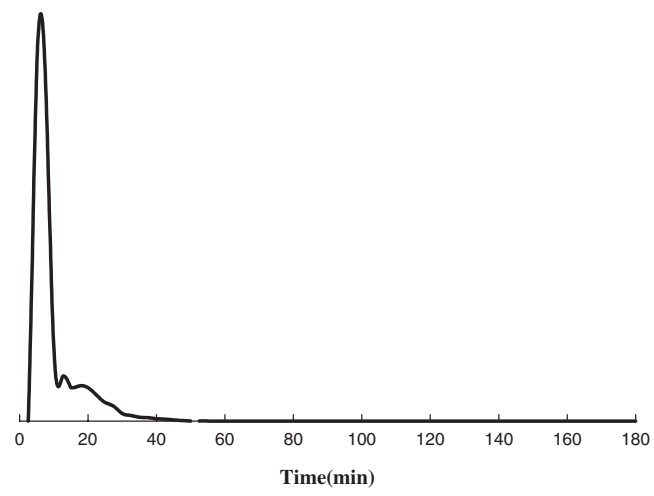

(c)Imprinted

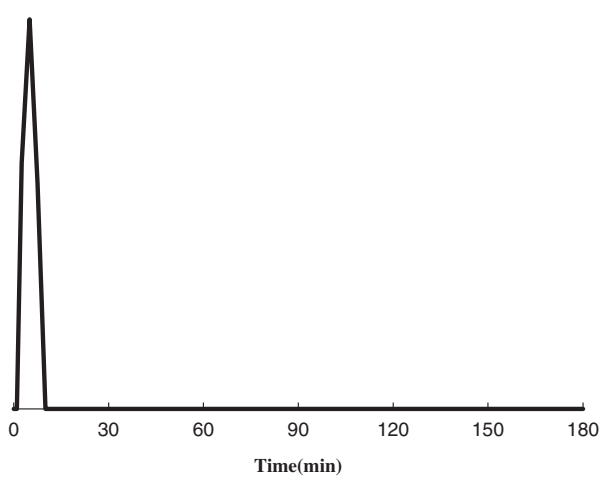

(b)Unimprinted

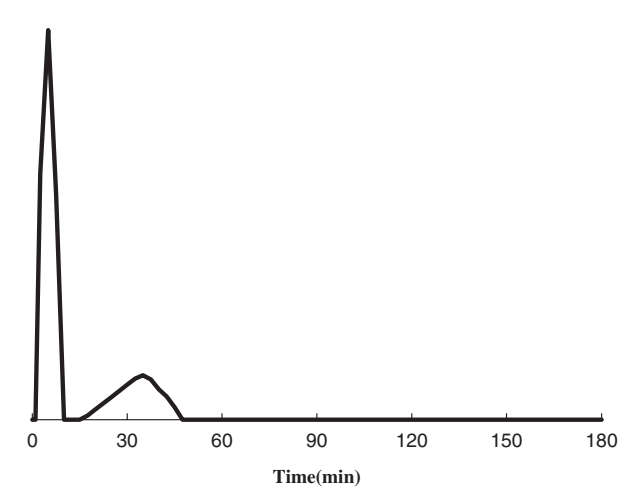

(d)Imprinted

Figure 6. HPLC profiles of N-Cbz-L,D-aspartic acid on the poly(4VP-co-EGDMA) microgels; Solvent ratio (acetonitrile-chloroform, $\mathrm{v} / \mathrm{v}$ ): (a) $10 / 90$ (b) $90 / 10$ (c) $10 / 90$ (d) $90 / 10$.

template molecule. 4VP was chosen as the functional monomer, on the basis that it has previously been shown to be efficient in the preparation of molecularly imprinted microgels selective for $\mathrm{N}$-protected amino acid. $^{16}$

It is assumed that 4VP interacts with the carboxy group in N-Cbz-L-aspartic acid by ionic interactions. $\mathrm{N}$-Cbz-L,D-aspartic acid was well resolved on this chiral stationary phases.

When each of N-Cbz-L-aspartic acid and N-Cbz-Daspartic acid injected in the HPLC, it was confirmed that the peak of N-Cbz-L-aspartic acid and N-Cbz-Daspartic acid was shown in Figure 5.

The effects of acetonitrile content on the separation of N-Cbz-L,D-aspartic acid enantiomers on the MIP microgels with an increase in the acetonitrile content, retentivity and enantioselectivity of N-Cbz-L,D-aspartic acid decreased was shown in Figure 6. This result suggests that hydrophobic interactions play an important role in the retention and enantio selectivity of N-Cbz-L,D-aspartic acid. ${ }^{23,24}$ So, imprinted microgels were found resolving power, but unimprinted microgels were not found resolving power.

\section{CONCLUSIONS}

The MIP Poly(4VP-co-EGDMA) microgels were synthesized from 4VP monomer and EGDMA as crosslinking agents using monodisperse linear PS seeds by the multi-step swelling method. From the results of this experiment were drawn conclusions as follows.

1. Particle size of the MIP poly(4VP-co-EGDMA) microgels were uniformly $4.0 \mu \mathrm{m}$ when the ratio of monomer/seed was $12.5 / 1,4.5 \mu \mathrm{m}$ when $16.7 / 1$, and $4.8 \mu \mathrm{m}$ when $25 / 1$.

2. According to varying the quantity of EGDMA used as crosslinking agent from 60 to 70,80 and $90 \mathrm{~mol} \%$, the MIP microgels were not formed when the concentration of crosslinking agent was $60 \mathrm{~mol} \%$ but monodisperse microgels were obtained when the concentration was above $60 \mathrm{~mol} \%$.

3. When the weight ratio of diluent/monomer was $1.5 / 1$, monodisperse microgels of $5.2 \mu \mathrm{m}$ were obtained, and the size of microgels increased 
with increasing the relative quantity of diluent to monomer.

4. The pore size of the MIP microgels was most uniform at $67.12 \AA$ when the weight ratio of monomer/seed was $25 / 1$, the mole ratio of EGDMA/monomer was $80 / 20$, and the weight ratio of diluent/monomer was $1.5 / 1$.

5. Unimprinted microgels were not found resolving power, but imprinted microgels were shown resolving power, when according to varying the quantity of acetonitrile-chloroform used as mobile phase from 10/90 to $90 / 10$.

\section{REFERENCES}

1. L. I. Kutin, T. Ellingsen, and J. Ugelstad, J. Chromatogr., 574, 1 (1990).

2. C. M. Cheng, J. W. Vanderhoff, and M. S. El-Aasser, J. Polym. Sci., Part A, 30, 145 (1992).

3. V. Lenaerts, Y. Dumoulin, and M. A. Mateesci, J. Controlled Release, 15, 39 (1991).

4. T. G. Park and A. S. Hoffman, Biotechnol. Bioeng., 35, 152 (1990).

5. T. Shiroya, M. Yasui, K. Fujimoto, and H. Kauagachi, Colloids Surf., 4, 175 (1995).

6. J. Steinke, D. C. Sherrington, and I. R. Dunkin, "Advances in Polymer Science," Springer Verlag, Berlin Heidelberg, 1995, Vol. 123, p 81.

7. V. P. Joshi, M. G. Gulkarni, and R. A. Mashelkar, Chem. Eng. Sci., 55, 1509 (2002).

8. G. Wulf, Angew. Chem., Int. Ed., 34, 1812 (1995).
9. M. Kempe and K. Mosbaha, J. Chromatogr., A, 664, 276 (1994).

10. H. Q. Shi, W. B. Tsai, M. D. Garrison, S. Ferrari, and B. D. Ratner, Nature, 298, 593 (1999).

11. P. Turkewitsch, B. Wandelt, G. D. Darling, and W. S. Powell, Anal. Chem., 70, 2025 (1998).

12. K. Hosoya, Y. Shirasu, K. Kimata, and N. Tanaka, Anal. Chem., 70, 943 (1998).

13. L. Schweiz, L. I. Andersson, and S. Nisson, Anal. Chem., 69, 1179 (1997).

14. T. Takeuchi, D. Fukuma, and J. Matsui, Anal. Chem., 71, 285 (1999).

15. L. I. Andersson and K. Mosbach, J. Chromatogr., 516, 313 (1990).

16. G. Wulff and M. Minarik, J. Liq. Chromatogr., 13, 2987 (1990).

17. V. Smigol, F. Svec, and J. M. J. Fréchet, J. Liq. Chromatogr., 17, 891 (1994).

18. L. R. Snyder and J. J., "Kirkland, Introduction to modern Liquid Chromatography, 2nd ed.," Wiley, New York, N.Y., 1979.

19. M. Petro, F. Svec, I. Gitsov, and J. M. J. Fréchet, Anal. Chem., 68, 315 (1996).

20. W. Rolls, F. Svec, and J. M. J. Fréchet, Polymer, 31, 165 (1990).

21. Q. C. Wang, F. Svec, and J. M. J. Fréchet, J. Polym. Sci., Part A: Polym. Chem., 32, 2577 (1994).

22. K. S. Kim, S. H. Kang, and J. S. Shin, J. Kor. Ind. \& Eng. Chem., 2, 45 (1996).

23. J. Haginaka, H. Takehira, K. Hosoya, and N. Tanaka, J. Chromatogr., 816, 113 (1998).

24. C. Yu and K. Mosbach, J. Chromatogr., 888, 63 (2000). 